\title{
A Study on the Motor Control of the Extraocular Superior Oblique and Inferior Rectus Muscles in Albino Rats Using the Fluorescent Tracers Fluorogold and DiI (1,1'-Dioctadecyl-3,3,3',3'-Tetramethylindo-Car- boyanine Perchlorate)
}

Daryanto Padmowijoyo ${ }^{1}$ and Takashi Yamadori ${ }^{2}$

\begin{abstract}
Abstrak
Persarafan motorik yang mengendalikan muskulus obliqus superior dan muskulus rektus inferior dikaji pada tikus putih dengan menggunakan dua jenis zat pelacak berlabel "fluorogold" (FG) dan "1,1'-dioctadecyl-3,3,3',3'-tetramethylindo-carbocyanine perchlorate (Dil) yang masing-masing disuntikkan pada kedua otot tersebut di atas. Hasil menunjukkan bahwa kedua otot tersebut dikendalikan oleh saraf motorik di dalam nukleus okulomotor (ipsilateral) dan nukleus troklearis (kontralateral), sehingga tampak beberapa neuron yang terlabel ganda pada kedua nukleus tersebut dan distribusi neuron berlabel pada kedua nukleus tampak berbeda- beda.
\end{abstract}

\begin{abstract}
The motor controls of the extraocular superior oblique and inferior rectus muscles were examined in the albino rats by using two fluorescent labelling tracers, fluorogold $(F G)$ and $1,1^{\prime}$-dioctadecyl-3,3,3',3'-tetramethylindo-carbocyanine perchlorate (DiI). Injection of the left inferior rectus and the right superior oblique muscles with FG and Dil, respectively, resulted in labelling the motor neurons within the ipsilateral oculomotor and contralateral trochlear nuclei. Some double labelled neurons were found in both nuclei and the distribution of labelled neurons on both nuclei varied among the cases.
\end{abstract}

Keywords: Superior oblique muscle, inferior rectus muscle, fluorescent tracers, fluorogold (FG), DiI.

\section{INTRODUCTION}

There have been a large number of investigations on the organization of the motor neurons controlling the extraocular muscles, both anatomically and physiologically. Recently, investigation on the motor control of the extraocular muscles have been made using the fluorescent labelling tracers.

Horseradish peroxidase (HRP) histochemistry was introduced by Strauss in 1957 and applied to the peripheral nervous system by Kristensson and Olson in 1971 and subsequently to the central nervous system by La Vail and La Vail in $1972 .{ }^{1}$ Since then, HRP has become one of the most frequently used method for tracing neural connectivity within the central nervous system in different species, e.g., cat, ${ }^{2-7}$ rabbit, $^{2}$ monkey, ${ }^{8-10}$ and rat, ${ }^{11-13}$ At that time, there have been no or few studies using other retrograde axonal transport tracers.

Since the introduction of HRP retrograde axonal tracers, however, a number of alternative axonal tracers have been developed as an aid the neuroscientist interested in studying neural connectivity. Fluorogold (FG), introduced by Schmued and Fallon ${ }^{14}$ in 1986, is a new fluorescent retrograde axonal tracer with numerous unique properties. Fluorogold (FG) as a neuronal tracer exhibits, among others, intense fluoresence, extensive filling of dendrite processes, minimal fading, no diffusion from labeled cells, and compatible with all other tested neurohistochemical techniques. $^{15}$

The fluorescent carbocyanine dye DiI (1,1'dioctadecyl-3,3,3',3'-tetramethylindo-carbocynanine perchlorate) introduced by Honig and Hume ${ }^{16}$ in 1989 ,

\footnotetext{
${ }^{I}$ Department of Histology, Faculty of Medicine, Gadjah Mada University, Yogyakarta, Indonesia

${ }^{2}$ First Department of Anatomy, Kobe University School of Medicine, Kobe, Japan.
} 
has been extensively used in cell biology, but as neuronal tracer it was used only recently. Honig and Hume $^{16}$ demonstrated that DiI and DiO molecules were excellent retrograde and anterograde tracers, non-toxic, whose major mechanism of action in vivo was axonal transport.

The reason for selecting the superior oblique and inferior rectus muscles in this study is to clarify the statement by Hebel and Stromberg ${ }^{17}$ that the superior oblique muscle is supplied only by the trochlear nerve alone and that the other extrinsic muscles of the eyeball including inferior rectus muscle are innervated by the oculomotor nerve. The aim of this study was to ascertain the motor control of the extraocular superior oblique and inferior rectus muscles by using the fluorescent labelling tracers FG and DiI.

\section{MATERIALS AND METHODS}

Animals. The experiments were conducted on 9 healthy albino rats of the Wistar strain (Japan Clea Co.), of both sexes, weighing between $250-430 \mathrm{~g}$.

Tracer injection. Each animal was anaesthetized with an intraperitoneal injection of $10 \%$ chloralhydrate (3 $\mathrm{mg} / \mathrm{kg}$ body weight). After attainment of deep anaesthesia, both left and right extraocular muscles were dissected out. The right superior oblique and the left inferior rectus muscles received small dose unilateral injections of DiI and FG labelling tracers, respectively. The volume of the injected solution tracers was 0.03 $0.04 \mathrm{ul}$ of DiI and FG, and the solution was delivered to the two muscles via a glass micropipette connected to a Hamilton's microsyringe over a period of $1-2$ minutes.

Perfusion. Postoperative survival time for each animal was 48 hours, during that time the animals were isolated one from another, given food and water ad libitum and deprived of light. The rats were then perfused intracardially with $10 \%$ formaldehyde in saline under $10 \%$ chloralhydrate deep anesthesia; thereafter the whole brain was removed. The brain was further immersed in freon and kept in the freezer for 10 minutes and cut serially in frontal slices of 20 um thickness using a cryostat. Two out of every five sections were mounted on glass slides. The specimens were air-dried in a dark box and then sections were microscopically examined under a fluorescent microscope (Nikon optiphot) with a filter system of $G$ and UV. Thereafter, the exact locations of the labelled neuron were depicted in a large map (18 X) of the brain section (camera lucida drawings).

\section{RESULTS}

Retrograde tracers DiI and FG labelling in the midbrain were routinely examined at a magnification of 25 - $100 \mathrm{X}$, and labelled neurons in individual midbrain section were depicted in a large map (18 X). Labelling with DiI and FG were examined on a Nikon optiphot microscope and a filter for $\mathrm{G}$ and $\mathrm{BV}$ was used to examine labelling with DiI and FG, respectively.

The results of these experiments demonstrated that retrograde transport of DiI and FG from the superior oblique and inferior rectus muscles, respectively, produced dense labelled motor neurons varying within the appropriate midbrain oculomotor and trochlear nuclei and thus serve as indicator of the precision of each muscle injection. The color of the labelled parent cell bodies of the neuron was a clear white upon a blue color background for FG labeled tracer, and unclear white upon a red color background for DiI labelled tracer. The groups consisting of the motor neurons innervating an individual muscle observed in the nucleus as elongated columns extending in a longitudinal direction. The position of each group in the transverse section varied according to the rostrocaudal level of the nucleus.

Inferior rectus muscle. Injection of $\mathrm{FG}$ into the left inferior rectus muscle resulted in labelling neurons occurred throughout the whole extent from the rostral to caudal (A to F) of the ipsilateral nucleus, and some of these labelled neurons were also found in the trochlear nucleus (Fig. 1 and Fig. 2 a). These were never found in the contralateral side. These labelled motor neurons in the oculomotor nucleus were observed as a cluster being formed by two groups which occupy the dorso-medial and ventro-lateral portions of the oculomotor nucleus. The distribution of labelled neurons, however, either labelled with DiI or FG in those nuclei varied among the individual section (Table 1).

Table 1. Distribution of retrogradely labelled neurons in the rat midbrain region following DiI and FG injections

\begin{tabular}{lrrrrrrrrrrrrr}
\hline Rat & \multicolumn{3}{c}{ A } & \multicolumn{2}{c}{ B } & \multicolumn{2}{c}{ C } & \multicolumn{2}{c}{ D } & \multicolumn{3}{c}{ E } & \multicolumn{2}{c}{ F } \\
No. & DiI & FG & DiI & FG & DiI & FG & DiI & FG & DiI & FG & DiI & FG \\
\hline 1 & -- & 5 & 1 & 1 & 3 & 3 & -- & 7 & 5 & 5 & 10 & - \\
2 & 3 & 25 & 1 & 22 & 1 & 14 & 3 & 14 & 2 & 10 & 9 & 7 \\
3 & 15 & 15 & 12 & 12 & -- & 6 & -- & 15 & -- & 5 & 8 & -- \\
4 & -- & 5 & 8 & 8 & -- & -- & - & -- & 15 & -- & 8 & - \\
5 & 11 & 9 & 21 & 21 & -- & 7 & - & 9 & 1 & 12 & 4 & 4 \\
6 & -- & 7 & -- & 12 & 10 & 12 & - & 7 & - & 15 & -- & - \\
7 & 2 & 2 & 10 & 10 & -- & -- & -- & -- & -- & -- & -- & -- \\
8 & 10 & 8 & 3 & 10 & 1 & 2 & -- & 10 & -- & -- & 15 & -- \\
9 & 8 & 7 & -- & 2 & 4 & -- & 3 & 3 & -- & 4 & 4 & 2 \\
\hline
\end{tabular}


ROSTRAL

A
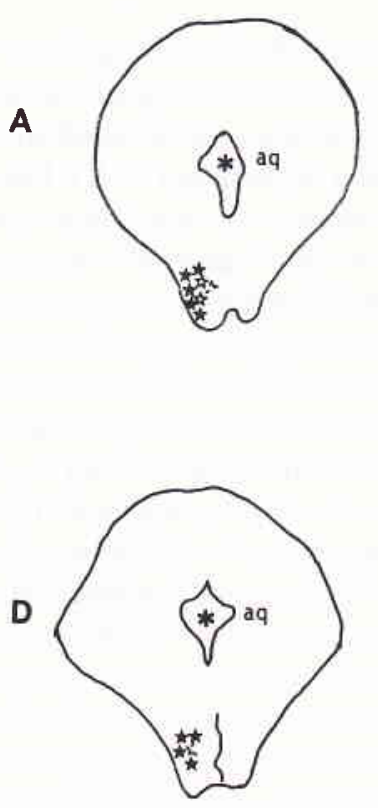

B

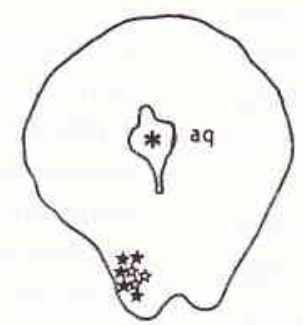

E

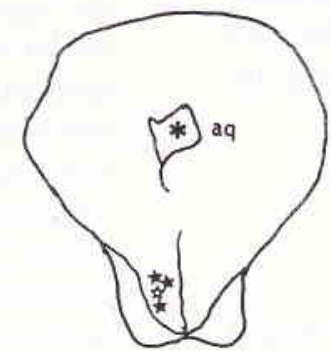

C

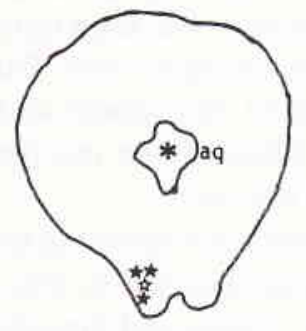

\section{CAUDAL}

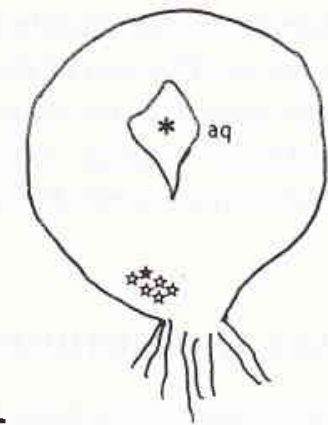

- FG * aq : aqueduct $*$ dil

Fig. 1. A camera lucida drawings of a rostral section of the rat midbrain showing a retrogradely labelled neurons from rostral $(A)$ to caudal $(F)$ levels, following Dil and FG injection into the right superior oblique and the left inferior rectus muscles. These retrogradely labeled neurons in $A$ is at the same levels as stereotaxic coordinate (according to Paxinos and Watson ${ }^{18}$ ) of IA (interaural) $1.96 \mathrm{~mm}$ and bregma - $6.04 \mathrm{~mm}$ and $F$ is at the same levels as $I \mathrm{~A} 1.70 \mathrm{~mm}$ and bregma $-7.30 \mathrm{~mm}$.
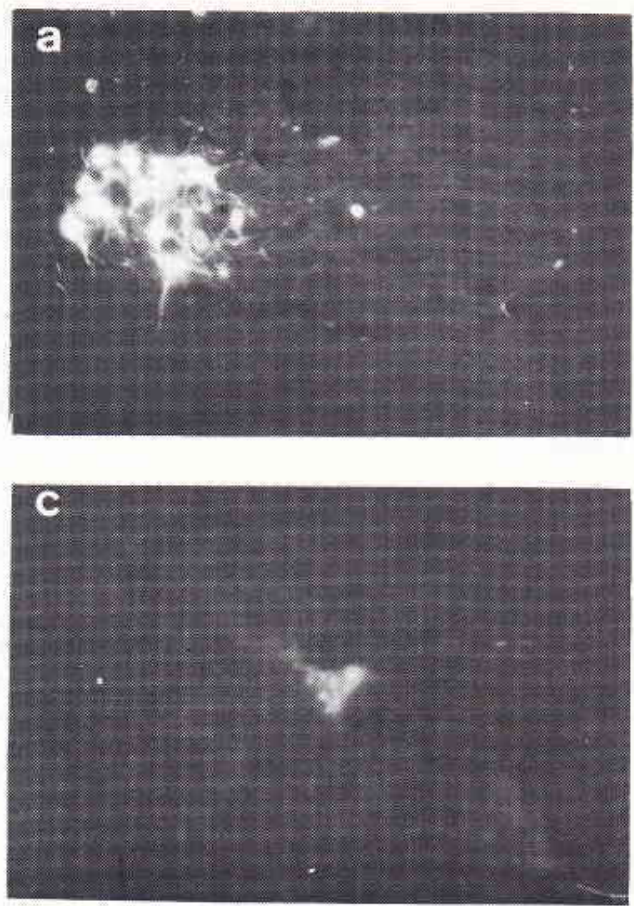
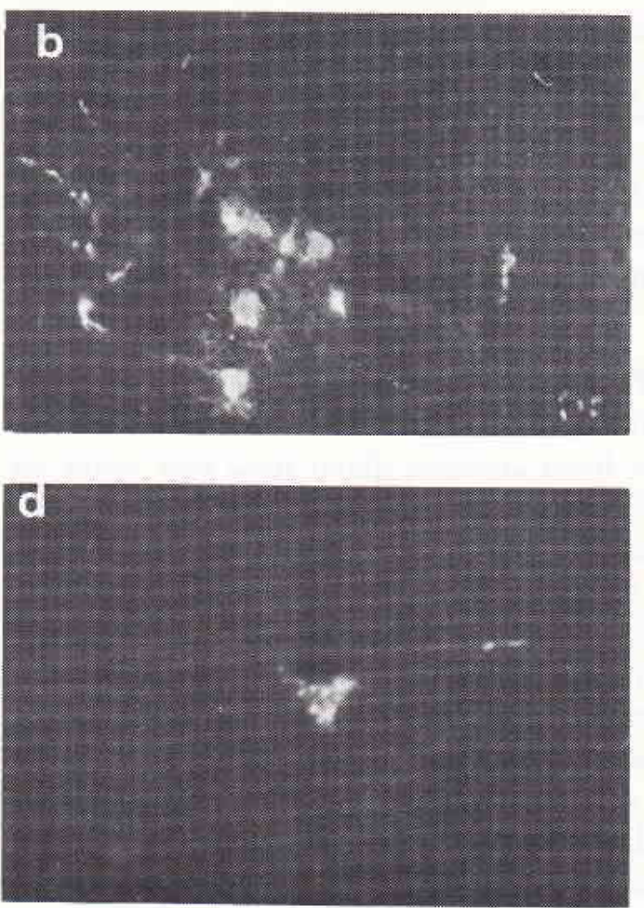

Fig. 2. A photomicrograph showing an example of the retrogradely labelled neurons in the ipsilateral oculomotor nucleus to FG injection (a), and in the contralateral trochlear nucleus to DiI injection $(b) .(c)$ and $(d)$ show examples of the retrogradely double labelled neurons to FG and DiI injections, respectively. 
Superior oblique muscle. Injection of DiI into the right superior oblique muscle resulted in labelling the motor neurons within the contralateral trochlear nucleus (Fig. 2b). A few double labelled neurons were observed in the rostral third of the oculomotor nucleus (Fig. 2c and d), but more labelled cells were found in the trochlear nucleus than in the oculomotor nucleus. Many of the trochlear neurons unlabelled by $\mathrm{DiI}$ procedure were presumably superior oblique motor neurons which have failed to take up sufficient tracer at their motor-end-plate, or the time to survive was not long enough for axonal transportation of DiI to reach the trochlear nucleus. The average of the labelled neuron ratio (labelled with DiI : FG) was $1: 2,2$ in the oculomotor nucleus and 4,4: in the trochlear nucleus. The percentage of the double labeled neurons in nine albino rats was about $4,0 \%$.

Table 2. The percentage of the double labelled neurons in the oculomotor and trochlear nuclei following DiI and FG injections

\begin{tabular}{cc}
\hline Rat no. & Percentage \\
\hline 1 & $3 \%$ \\
2 & $5 \%$ \\
3 & $4 \%$ \\
4 & $4 \$$ \\
5 & $6 \%$ \\
6 & $3 \%$ \\
7 & $4 \%$ \\
8 & $3 \%$ \\
9 & $5 \%$ \\
\hline
\end{tabular}

\section{DISCUSSION}

In this study the motor controls of the extraocular superior oblique and inferior rectus muscles in albino rats were examined by two fluorescent labelling tracers Dil and FG, and using one of the neuroanatomical-tract tracing methods, developed by Robards and Heimer. ${ }^{15}$

Injection of a fluorescent labelling tracer DiI and FG respectively, into the right superior oblique and left inferior rectus muscles, in nine adult albino rats of the Wistar strain, demonstrated that, either DiI or FG, has labelled the motor neuron in the oculomotor and trochlear nuclei. The motor neurons in the oculomotor and trochlear nuclei were verified by the retrogradely transported DiI and FG. This indicated that DiI and FG were taken up by the axon terminal in those muscles and transported retrogradely to the parent cell bodies in those nuclei.

The organization of the extraocular motor neurons demonstrated in this study shares dissimilarities and similarities with previous investigations. The similarities with previous investigations are the entire contralateral innervation of the superior obli- que muscle and the entire ipsilateral innervation of the inferior rectus muscle in rat, ${ }^{11-13} \mathrm{cat}^{2-7}$ rabbit, $^{2}$ or monkey. ${ }^{8-10}$

Similar findings have been reported by investigator in rats by means of neuro-anatomical-tract tracing methods and using HRP method. With this method $O \mathrm{da}^{13}$ found that the muscles supplied by the neurons on both sides of oculomotor and trochlear nuclei were the superior oblique and inferior rectus.

The dissimilarity with the other study results, is that motor neurons of the superior oblique muscle were also found in the oculomotor nucleus and the motor neurons of the inferior rectus muscle found in the trochlear nucleus, even though only a few double labelled neurons (4\%) were observed in the oculomotor and trochlear nuclei.

This investigation demonstrates that the motor control of the extraocular superior oblique and inferior rectus muscles in albino rats is in the oculomotor and trochlear nuclei.

\section{Acknowledgments}

This study was supported by ICMR through the JSPS Cooperation Program, in the year of 1994. The authors greatly appreciate for guidance and technical expertise of Kai Dong, M.D., Ph.D., Hanie M. Youssef, M.D. and Mr. Faried Ahmed, M.Sc.

\section{REFERENCES}

1. Mesulam MM. Tetramethyl bunzidine for horseradish peroxidase neurohistochemistry: A non-carcinogenic blue reaction-product with superior sensitivity for visualizing neural afferents and efferents. J Histochem Cytochem 1978; 26(2):106-17.

2. Akagi Y. The localization of the motor neurons innervating the extraocular muscles in the oculomotor nuclei of the cat and rabbit, using horseradish peroxidase. J Comp Neurol 1986; 247:133-43.

3. Buisseret-Delmas C, Buisseret P. Central projections of extraocular muscle afferents in cat. Neurosci Let 1990; 109:48-53.

4. Graybiel AM, Hartwieg EA. Some efferent connections of the oculomotor complex in the cat: an experimental study with tracer techniques. Brain Res 1994; 81:543-51.

5. Ogasawara K, Onodera S, Shiwa T, Ninomiya S, Tazawa Y. Projections of extraocular muscle primary afferent neurons to trigeminal sensory complex in the cat as studied with the transganglionic transport of horseradish peroxidase. Neurosci Let $1987 ; 73: 242-6$.

6. Porter JD, Spencer RF. Localization and morphology of cat extraocular muscle afferents by retrograde transport of horseradish peroxidase. J Comp Neurol 1982; 204:56-64.

7. Tarlov E, Tarlov SR. The representation of extraocular muscles in the oculomotor nuclei: Experimental studies in the cat. Brain Res 1971; 34:37-52. 
8. Porter JD. Brainstem terminations of extraocular muscle primary afferent neurons in the monkey. J Comp Neurol 1986; 247:133-43.

9. Porter JD, Guthrie BL, Sparks DL. Innervation of monkey extraocular muscles: localization of sensory and motor neurons by retrograde transport of horseradish peroxidase. $\mathrm{J}$ Comp Neurol 1983; 218:208-19.

10. Spencer RF, Porter JH. Innervation and structure of extraocular muscles in the monkey in comparison to those of the cat. J Comp Neurol 1981; 198:649-65.

11. Glicksman MA. Localization of motor neurons controlling the extraocular muscles of the rats. Brain Res 1980; 188:5362.

12. Leichnetz GR, Hardy SGP, Carruth MK. Frontal projections to the oculomotor complex in the rat: $A$ retrograde and anterograde HRP study. J Comp Neurol 1987; 263:389-99.
13. Oda $Y$. The nerve center of the rat $o$ cular muscles as studied using horseradish peroxidase. Okijimas Folia Anat Jpn 1981; $58(1): 14-42$.

14. Schmued LC, Fallon JH. Fluoro-gold: a new fluorescent retrograde axonal tracer with numerous unique properties. Brain Res 1986; 377:147-54.

15. Robards MJ, Heimer L. Neuroanatomical-tract tracing methods. New York; Plenum Press, 1981.

16. Honig MG, Hume RI. DiI and DiO: versatile fluorescent dyes for neural labelling and pathway tracing. Trend in Neurosecience (TIN), 1989; (12)9:333-41.

17. Hebel R, Stromberg MW. Anatomy of the laboratory rat Philadelphia: The Williams and Wilkins, 1976.

18. Paxinos G, Watson C. The rat brain, in stereotaxic coordinates, New York Academic Press Harcourt Brace Jovanovich Publishers, 1989. 